\section{TOMB OF AN ANCIENT EGYPTIAN PHYSICIAN.}

\section{To the Editor of THE LANCET.}

SIR, - In THE LANCET of Jan. 11th in your annotation on "The Burial Customs of Ancient Egypt" by Professor John Garstang you mention the following in connexion with the deceased physician's tomb-viz, , that "varions and many as were the objects deposited beside his body only two of these can in any way be considered as connected with his vocation-namely, a set of writing implements, consisting of a writing tablet and a pen-box"; also that "unfortunately no -sritten notes survive upon the palette." The significance of the pen box and tablet in or upon the tomb seems to be misunderstood. They are not scarce in any of the bigger towns of India and Arabia. Those who have visited the well. known tombs of the Moghul Emperors, Akbar and ShahJehan, and their wives, must have noticed the carved pen box and the adjacent tablet, these being purely symbolic, the pen for the man-the active agent and doer of things; the unwritten slate representing the woman-i.e., the passive agent, the slave and complement of the man.

I am, Sir, yours faithfully,

L. Jones, M.R.C.S. Eng., L.R.C.P. Lond.

Sialkote, India

\section{THE SITUATION AT THE HAMPSTEAD GENERAL HOSPITAL. \\ To the Editor of THE LANCET.}

SIR,-I think the time has come when an attempt should be made to remove the impression that this hospital has been guilty of some crime against society in general or the medical profession of Hampstead in particular, and in order to do this I beg the hospitality of your columns, although in telling the story I am largely repeating what has already appeared editorially in your columns.

The Hampstead Hospital was started in 1882 with a few beds for patients able to contribute a little towards their support, and was most successfully officered by certain general practitioners in its neighbourhood. It is misleading, however, to describe it as a "cottage hospital." The free beds, which have existed since 1894, have always been in charge of the regular medical staff; only the "contributory beds" have been available to other practitioners. In the new hospital there is no intention of taking away this privilege from the local members of the profession.

As a result of increased demands the first portion of the new hospital was erected two years ago with 64 beds, and in these excellent quarters the hospital has continued to receive the willing and able services of the same staff of general practitioners. At the opening ceremony it was announced that a sum of $£ 10,000$ was required to free the hospital from debt and that a further sum of $£ 15,000$ would complete the scheme to provide a total of 110 beds. An immediate response was received, Sir Henry Harben announcing that he was authorised by an anonymous donor to say that $£ 20,000$ would be forthcoming if the remaining $£ 5000$ require 1 were obtained. To avoid diverting support from the general funds of the hospital by an appeal for this sum the council laid the conditions of this special offer before King Edward's Hospital Fund and received a promise from them to provide the sum of $£ 5000$. At the same time the King's Fund suggested that the growing importance of the hospital made it desirable for it to adopt a similar constitution for its medical staff to that of all other general hospitals in London.

At a later date the King's Fund having had its attention drawn to the condition of the North. West London Hospital the buildings of which were considered unfit for continued treatment of in-patients, and the committee of that institation being unable to see its way to obtain an adequate sum for rebuilding, suggested that an amalgamation of that hospital with the Hampstead General Hospital might be arrived at, an out-patient department being maintained solely in Kentish Town and all in-patients being received at the Hampstead Hospital. The King's F and decided that as it was proposed that the Hampstead General Hospital should henceforth be reckoned, as was the North-West London Hospital, amongst the Metropolitan hospitals, it should be a condition of the amalgamation that the Hampstead General Hospital should be officered by physicians and surgeons of recognised consulting rank. In a canvass on this proposal, by means of a series of questions issued to the members of the local profession, the opinions expressed for and against the change were almost equal, but the result was distinctly unfavourable to the scheme of a mixed staff of general practitioners and physicians and surgeons in consulting practice. It was eventually resolved by the council of the hospital to make the change to a staff consisting of physicians and surgeons in consulting practice, with definite provision for a term of continued service in the case of members of the existing staff of general practitioners. These terms vere accepted as satisfactory by the members of the existing staff, except as regards the decision, arrived at later under the amalgamation scheme, that the two junior members in charge of out-patients (being in general practice), who were entitled to further service of 13 years each, should not be eligible for promotion to in-patient posts.

As regards the amalgamation proposals, I may say that on April 10th, 1907, a committee of the local medical profession and the medical staffs of the Hampstead and NorthWest London Hospitals reported to a meeting of the British Medical Association (Hampstead division) that the proposed amalgamation with the North-West London Hospital was desirable from the public point of view (on certain conditions). On the amalgamation being decided upon, the medical staff placed themselves in line with the local practitioners who were opposed to the changes. Since then, as your readers are aware, a canvass of local practitioners has been made by the Hampstead division of the British Medical Association, resulting in a vote which in their view justified their sending a "warning notice" to the British Medical Journal which was accepted.

I may say that the council of the hospital appreciate most highly the valuable services of the present acting medical staff and also their generosity in consenting to act until successors could be appointed; but the council nevertheless much regret that when arrangements had been made for the retention of these gentlemen on the staff, on a plan but slightly modified from that which had been approved by them, they should suddenly have changed their mind and joined with others in a soheme for preventing their place being filled by such persons as the King's Fund suggested, and financial reasons had compelled the council to accept. The hospital cannot get the promise of the necessary financial support in Hampstead-it will need three times as large an income as that which it has been able to count on-and it has no alternative but to accept the substantial and welcome help offered by the King's Fund, and at the same to submit to its conditions which, after all, in a place like London, are not unreasonable.

In conclusion, I would say that the council of the hospital have no quarrel with the medical profession in Hampstead, nor, on the other hand, have they any fear, doubt, or hesitation in adopting the course which the successful evolu. tion of the hospital has thrust upon them. I am, Sir, yours faithfully,

ERnest Colluins, Chairman of the Council, Hampstead General Hampstead, Feb. 19th, 1908 .

\section{THE PRESENT PROSPECTS OF THE MEDICAL PROFESSION.} To the Editor of THE LANOWT.

SIR,-Continuing on the ethical lines which we as a profession have been following the answer to the heading of this correspondence would be, "Not much." The letter of "Virtutem Sequor" contains much which can be agreed with, particularly that part in which he deals with so-called "specialists." Some while ago you headed a correspondence, "What is a specialist?" To this question you had replies but no definition. I will, with your kind permission, essay that needed definition. "A specialist in a department of the healing art is one who, knowing thoroughly the entire human body and its ailments, is able to devote his attention to that department for which his skill and dexterity are most suited." Instead of the above, "specialism," as now practised, should be defined as follows: "A 'specialist' is a person whose knowledge needs increasing and skill perfecting in that department in which he exclusively practises, presuming upon a superficial knowledge of the human body and its ailments generally." The contrast is as striking as true. The letter of "Half-and-Half" centres the "boll's-eye" and 
will meet with the endorsement of every one who has been a general practitioner and has kept himself abreast of the times and is striving to rise, and with his rise improve the status and prospects of the profession. The first and true definition of a specialist applies to the risen general practitioner, the latter definition applies to the " hospital-appointment-made-specialist" who yet has his knowledge to gain, who has no skill, yet who professes to sell that which he does not possess. From the above you can see that the prospects for those who have worked hard as general practitioners is certainly " not much." Your late most honourable campaign in the Law Courts in defence of the rights of the public and of those of us who have to work hard for our daily bread was partly due to the condition of affairs dealt with by both "Virtutem Sequor" and "Half-and-Half."

Did general practitioners keep themselves abreast of the times, and were "specialists" (?) more really "specialists" and less "exclusivists" (learning their "one horse-shay racket"), there would be no lay advertisers of this and that "specific" for one disease and another. Is not "specialism" as now practised a species of quackery? A good "general practitioner" is a true "specialist in many departments," a modern "specialist" is a one-string fiddler in an orchestra who does not know his notes. Let me ask "Virtutem Sequor" one question. Is it worse to advertise rather than starve and become a financial defaulter following an unwritten law which no one really cares a straw about, or is it worse to be ethical (with your mouth only), the while doing all you can to hinder and ruin the prospects of your fellow man and brother (?) as is practised in London at hospital elections? Which of the two pictures will show painted the blacker sheep? The frank, open advertiser, according the same to his fellow man, or the hypocrite who does all he can to damn the career of a general practitioner and pitchforks a young "specialist" (?) into a post to keep out the other fellow? All those things of which "Half-and-Half" ably writes have I done, and more. I will therefore finish what he has left unsaid. He says, "It is, I think, forgotten by many that each patient sent by them to a "specialist" means the loss to them, only too frequently, not only of that patient but of all that patient's friends who have, or think they have, any disease affecting that particular region of the body." Let us now continue (in my own words), "and of those who have not, but have ailments of other parts, will that 'specialist' send on direct to his brother 'specialists' in accordance with their custom of mutual 'back-scratching,' and so on, till soon there is no practice left for the general practitioner who sent the first case." If it is borne in mind that these so-called "specialists" are daily engaged in cutting the throats of the lesser general practitioners in the out-patient departments of hospitals, besides distributing their richer patients amongst themselves, we must repeat " Not muoh." In a recent issue you printed an article showing the existence of a decided schism in the Liverpool district between general practitioners and hospital practitioners who are advertised by their (?) hospital and I make bold to say that the London general practitioner is a greater fool than I take him for if the same does not occur soon in London.

Strangely enough, a letter by "F.R C.S." entitled "The Responsibillty for the Anæsthetic" shows up another phase of the "prospects of the profession," Why does the general practitioner asked to be allowed to give the anæsthetic? As one who has been a general practitioner let me answer. To be able to retain a hold on his patient, as a patient, and not to be entirely cut out of that which his honesty has put into the hands of "F.R C.S." A general practitioner nowadays is a tout (at his own expense), paying his rent, rates, taxes, and keeping up a position, purely in order to find cases with fat fees for the "specialist." The "specialist " comes in, whisks the patient off to a nursing home, and out goes the poor wretch of the general practitioner to his debts; those that he owes and those that are owed to him. In nine cases out of ten, the general practitioner has money owing to him by the patient for present and past illnesses, the "specialist" comes in, and the patient begs, borrows, or steals the wherewithal to pay the fee demanded. Off goes the specialist with the "ready" and the general practitioner has only debts owing to him, and a useless patient for some time to come, till the money borrowed to pay the "specialist" is repaid. "I have had some" and got heartily sick of it. The more fair and equitable rule is the one which I now follow, and perhaps "F.R.C.S." will please note and practise it. When the case needs operation my practice is as follows : refuse the request except the general practitioner be a skilled anæsthetist, but ask the general practitioner to assist at the operation and undertake the major part of the after attendance, and for his services give him "down on the nail " onethird of the fee agreed upon for the operation, for he has earned it. So that "F.R.C.S." can still have his skilled anresthetist and at the same time feel that the general practitioner gets something for his wife and children and is not left, as he often is, a "skinned eel" with an "invitation to dinner." More often than not that third part of the operation fee will be the only money the general practitioner will ever see out of the case. Let this plan be adopted universally and there will then, at any rate, be some prospects for both general practitioner and specialist. Mutual help and support should be the watchword, not selfish hindrance and throat-cutting, grasping greed.

I am, Sir, yours faithfully,

F. W. Forbes-Ross, M.D. Edin., F.R.C.S. Eng.

Harley-street, Feb. 16th, 1908.

\section{To the Editor of THE LANCET.}

SIR,- So far as the general public is concerned "Virtutem Sequor" raises a very important issue in his remarks re con. sultants. What constitutes a consultant, and to what fees is he entitled? A friend of mine afflicted with failing eyesight had occasion to go to an optician who advised him to go to a certain oculist. This latter gentleman examined the eyes, prescribed glasses, and charged $£ 22 s$. On subsequently referring to the Medical Directory it was found that the doctor consulted had merely ordinary qualifications and was not, nor ever had been, attached to any ophthalmic hospital.

Now, Sir, as a mere layman, what I want to know is, how can the public be protected from this kind of thing? The general impression amongst us is that a consultant is a gentleman of the highest qualifications (e.g., F.R.C.S.) and who has a hospital appointment. I appeal to you, Sir, for an ex cathedra pronouncement on the matter.

$$
\text { I am, Sir, yours faithfully, }
$$

Feb. 14th, 1908. WaLter Carter.

\section{THE INACCURATE DOSAGE OF MEDICINES:}

Zo the Editor of THE LANCET.

SIR,-Your remarks in an annotation in your issue of Feb. 15th, p. 512, on "The Inaccurate Dosage of Medicines," due to the different sizes of bottles supposed to be two, four, six, and eight ounces, are most appropriate, but there is also, I think, a still greater reform required, that all tinctures should be so prepared that the same quantity of each should represent an adult dose, say one drachm. Infusions might be one ounce, wines one drachm, and so on, with spirits, pills, powders, \&c. Surely wholesale druggists could arrange this, and so reduce the dangers and difficulties in dispensing medicines. There is often some uncertainty in remembering the correct doses of drugs other than those habitually used, and a desirable preparation may be omitted from the prescription through this cause.

Dorney, Windsor, Feb. 16th, 1908.

J. H. WATERS.

\section{RECEPTION HOUSE FOR RECENT CASES OF INSANITY. \\ To the Editor of THE LANCET.}

SIR,- Through the medium of your valuable columns and the columns of your less specialised contemporary the Sunday Cnroniole, I have recently learnt that some striking "advances" have been made in the treatment of mental diseases in Scotland-namely, (1) through the medium of a structure of corrugated iron and "compo" boarding, \&c., and (2) some open air.

I regret that (owing possibly to a defect within myself), having carefully read all the details mentioned in $\mathrm{Dr} . \mathrm{H} . \mathrm{C}$. Marr's paper in your issue of Feb. 8th, I entirely fail to see, on analysis, any difference in the practice adopted at Woodilee to that in use here (in the southern portion of England) for many years, or in probably 90 per cent. of other asylums in England, with the exception that : 1 . Only few asylums have female nurses in the male wards, and this may, or may not, be an important factor, though I personally have yet to feel that yearning desire to add one to the female staff. 2. That 